\title{
Atributos de solo e de plantas afetados pelo manejo da pastagem anual de inverno em sistema de integração lavoura-pecuária
}

\author{
Soil and crop attributes affected by winter pasture management in integrated crop-livestock system
}

\author{
Milton da Veiga ${ }^{\mathrm{I}}$ Leandro Durigon ${ }^{\mathrm{II}}$ Carla Maria Pandolfo ${ }^{\mathrm{III}}$ Alvadi Antonio Balbinot Junior ${ }^{\mathrm{IV}}$
}

\section{RESUMO}

O uso continuado do sistema de integração lavoura-pecuária pode promover alterações em atributos físicos do solo, bem como afetar a produtividade das culturas semeadas em sucessão à pastagem. O objetivo deste trabalho foi avaliar o efeito de formas de semeadura e do intervalo entre a retirada dos animais e a dessecação da pastagem anual de inverno sobre atributos físicos do solo, fitomassa aérea remanescente da pastagem e produtividade das culturas semeadas em sucessão. Foi instalado um experimento em propriedade rural em Campos Novos, SC, que utiliza o sistema integração lavoura-pecuária, onde foram aplicados os seguintes tratamentos: duas formas de semeadura da pastagem no outono (semeadura direta sem e com posterior revolvimento do solo com grade niveladora), alocados nas parcelas principais, $e$ quatro intervalos de retirada dos animais antes da dessecação da pastagem (retirada dos animais aos 28, 14 e 1 dia antes da dessecação e testemunha, sem pastejo), alocados nas subparcelas. Foram determinados a fitomassa aérea de pastagem remanescente por ocasião da dessecação, os atributos físicos do solo após a dessecação da pastagem e o rendimento de grãos de soja e milho. A forma de semeadura da pastagem anual de inverno não afetou os atributos físicos do solo e o rendimento das culturas de soja e milho cultivadas em sucessão à pastagem, enquanto o aumento do intervalo entre a retirada dos animais e a dessecação aumentou a fitomassa aérea remanescente da pastagem por ocasião da dessecação.

Palavras-chave: pastejo contínuo, compactação do solo, soja, milho, sistema plantio direto.

\begin{abstract}
Continued use of the crop-livestock system in agricultural areas can promote changes in soil physical attributes, as well as affect the productivity of crops grown in rotation with pasture. The aim of this study was to evaluate the effects of methods of sowing and the interval between the withdrawal and desiccation of pasture on soil physical attributes, aboveground biomass of pasture and productivity of crops sown in succession. It was conducted an experiment in a rural property in Campos Novos, which uses the crop-livestok system, with the following treatments: two types of pasture seeding in autumn (direct seeding without and with subsequent soil harrowing), allocated in main plots, and four intervals of removing animals from the pasture before desiccation (removal of the animals at 28, 14 and 1 day before the desiccation and control, without grazing), allocated as subplots. It was determined the aboveground biomass of pasture, the soil physical attributes after desiccation of grassland and yield of soybeans and corn. The form of winter pasture seeding does not affect the soil physical attributes and crop productivity, while increasing the interval between the withdrawal and desiccation of winter pasture increases the production of the aboveground biomass of the pasture.
\end{abstract}

Key words: continuous grazing, soil compaction, soybean, corn, no-tillage system.

\section{INTRODUÇÃO}

No Sul do Brasil, é muito utilizado o sistema integração lavoura-pecuária (SILP), caracterizado pelo

'Empresa de Pesquisa Agropecuária e Extensão Rural (Epagri), Estação Experimental de Campos Novos (EECN), CP 116, BR 282, km 338, Trevo, 89620-000, Campos Novos, SC, Brasil. E-mail: milveiga@epagri.sc.gov.br. Autor para correspondência.

II Autônomo, Campos Novos, SC, Brasil.

"IIEpagri, EECN, Campos Novos, SC, Brasil.

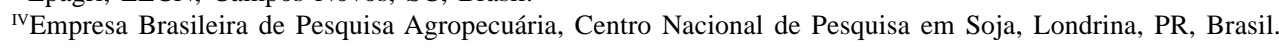


cultivo de pastagens anuais de inverno, manejadas sob pastejo direto, em alternância com culturas para produção de grãos no verão. A principal razão para o uso desse sistema é de ordem econômica, pela falta de opções de culturas comerciais para cultivo no outono/ inverno, ou pela redução da oferta de forragem nas pastagens perenes de verão (BALBINOT JUNIOR et al., 2009a). A viabilidade econômica do SILP em sistema de semeadura direta (SSD) foi comprovada por FONTANELI et al. (2006), tanto para as culturas comerciais como para a engorda dos bovinos no período invernal no planalto do Rio Grande do Sul.

O uso continuado do SILP, no entanto, pode promover alterações em atributos físicos do solo em função do pisoteio dos animais durante o pastejo, tais como aumento da densidade e redução da porosidade, ambos indicadores do aumento do estado de compactação do solo. Essas alterações, contudo, ocorrem com maior intensidade na camada de $0-10 \mathrm{~cm}$ de profundidade (LANZANOVA et al., 2007) e muitas vezes não atingem valores críticos que possam limitar a produtividade de culturas anuais cultivadas na sequência (SILVA et al, 2000; SPERA et al., 2004 e 2009). Alguns autores não encontraram diferenças significativas nos atributos estudados entre sistemas com e sem SILP(SILVA et al., 2000; SPERA et al., 2004; BALBINOT JUNIOR et al., 2009b) ou entre sistemas de manejo dos animais com diferentes alturas de corte da pastagem sob pastejo direto (FLORES et al., 2007). A produção da cultura de soja cultivada em sucessão pode, inclusive, ser maior na área pastejada em relação a não pastejada, desde que utilizada baixa intensidade de pastejo (LUNARDI et al., 2008).

A forma de implantação da pastagem é um dos aspectos que pode afetar o grau de compactação das lavouras manejadas sob SILP, sendo normalmente utilizadas a semeadura direta ou a semeadura a lanço e incorporação das sementes com grade. Esse último sistema ainda é o mais utilizado para implantação de pastagem de inverno em pequenas e médias propriedades no Sul do Brasil, resultando em revolvimento e redução da resistência à compactação da camada superficial do solo e, consequentemente, aumento do potencial de compactação pelo pisoteio dos animais (FLORES et al., 2007; VEIGA et al., 2007). A intensidade e a profundidade de revolvimento do solo dependem do equipamento utilizado (grade niveladora ou aradora), de sua regulagem (mais aberta ou mais fechada) e da quantidade e tipo de palha existente sobre o solo por ocasião da operação. A palha remanescente na superfície do solo, por sua vez, atenua a pressão aplicada pelo tráfego de máquinas e de animais na proporção direta da sua quantidade (BRAIDA et al., 2006), reduzindo o potencial de compactação do solo.

O intervalo transcorrido entre a retirada dos animais da lavoura e a dessecação da pastagem (intervalo de diferimento) também é importante para a definição do estado de compactação do solo, mas é um aspecto ainda pouco estudado. Isso porque, nesse intervalo, ocorrerá rebrote da pastagem, com maior desenvolvimento do sistema radicular e produção de fitomassa aérea que, após a dessecação, permanecerá sobre a superfície do solo. Nesse intervalo, também ocorrem ciclos de umedecimento e secagem do solo, que promovem variação nas tensões internas deste, podendo reduzir expressivamente o estado de compactação na camada superficial (HORN \& ROSTEK, 2000).

Em função da pouca disponibilidade de estudos sobre o efeito de formas de semeadura da pastagem de inverno e do intervalo entre a retirada dos animais e a dessecação da pastagem anual de inverno sobre atributos da pastagem, da cultura comercial de verão e do solo, foi desenvolvido o presente estudo em sistema de integração lavoura-pecuária com gado de corte sob pastejo contínuo, em lavoura manejada sob sistema de semeadura direta.

\section{MATERIAL E MÉTODOS}

O experimento foi conduzido dentro de uma lavoura localizada em uma propriedade rural no

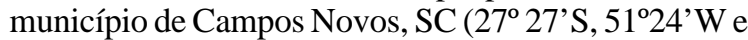
987m de altitude), em solo da classe Nitossolo Vermelho Distrófico (EMBRAPA, 2004), com declividade média aproximada de $12 \%$, e clima mesotérmico úmido com verão ameno, do tipo Cfb, de acordo com a classificação de Köppen (PANDOLFO et al., 2002). A área do experimento apresentava, por ocasião de sua implantação, 6,1 de pH em água, 24,2 $\mathrm{mg} \mathrm{dm}^{-3}$ de P extraível, 223mg dm ${ }^{-3}$ de $\mathrm{K}$ trocável, $8,9 \mathrm{cmol}_{\mathrm{c}} \mathrm{dm}^{-3} \mathrm{de}$ Ca trocável, 3,3 $\mathrm{cmol}_{\mathrm{c}} \mathrm{dm}^{-3}$ de $\mathrm{Mg}$ trocável, $3,8 \%$ de matéria orgânica e $610 \mathrm{~g} \mathrm{~kg}^{-1}$ de argila.

O delineamento experimental utilizado foi em blocos completos casualizados, com parcelas subdivididas e quatro repetições. Nas parcelas principais, de $10 \times 20 \mathrm{~m}$, foram aplicados dois tratamentos de formas de semeadura da pastagem de inverno: semeadura direta com semeadora equipada com duplos discos desencontrados, sem e com revolvimento adicional do solo com grade niveladora. Em subparcelas de $5 \times 10 \mathrm{~m}$, foram aplicados quatro tratamentos de intervalos entre a retirada dos animais e a dessecação da pastagem (intervalos de diferimento): sem pastejo (SP) e retirada dos animais aos 28, 14 e um dia antes da dessecação (respectivamente 28DAD, 14DAD e 01DAD).

Nos dois primeiros anos de avaliação, foi utilizada uma rotação de culturas com aveia preta (Avena strigosa Schreb)/ soja (Glicyne Max L; Merril) e aveia preta + ervilhaca (Vicia sativa)/milho (Zea mays L.). A semeadura da ervilhaca foi realizada a lanço, utilizandose $60 \mathrm{~kg} \mathrm{ha}^{-1}$, e a da aveia preta com semeadora para semeadura direta, utilizando-se espaçamento entrelinhas de $0,17 \mathrm{~m}$ e $100 \mathrm{~kg} \mathrm{ha}^{-1}$ de sementes. Imediatamente após a semeadura dessas espécies, foi passada, nas parcelas com revolvimento do solo, grade niveladora de levante hidráulico tipo tanden. 
Os animais foram colocados na lavoura aos 55 e 74 dias após a semeadura da pastagem, respectivamente, no primeiro e segundo ano. A partir de então, foram mantidos continuamente na lavoura com lotação variável, calculada a partir da massa dos animais por ocasião de cada ingresso e/ou retirada da lavoura onde estava situado o experimento, considerandose a massa de $450 \mathrm{~kg}$ por unidade animal (UA). As parcelas sem pastejo foram isolados com cerca eletrificada desde a semeadura da pastagem e os animais tiveram livre acesso às demais parcelas durante o período de pastejo até a data do respectivo diferimento, quando também foram isolados com cerca eletrificada. No dia correspondente ao último diferimento (01DAD), foram coletadas amostras da fitomassa aérea da pastagem remanescente e, no dia posterior, realizada a dessecação em toda a área. A fitomassa aérea remanescente da pastagem foi determinada através do corte da pastagem, rente ao solo, em uma área de $0,25 \mathrm{~m}^{2}$ por parcela, a qual foi seca em estufa a $60^{\circ} \mathrm{C}$ até massa constante e calculada a massa seca em base de $\mathrm{kg} \mathrm{ha}^{-1}$.

A semeadura das culturas de verão foi realizada com semeadora para semeadura direta equipada com disco de corte e sulcador, sendo a soja (Coodetec 23) com espaçamento entrelinhas de 0,45m e 12 sementes por metro linear e o milho (Pionner 30F53) com 0,70m entrelinhas e 4,5 sementes por metro linear. A adubação e os tratos culturais e fitossanitários, realizados a partir de então, foram os mesmos aplicados na lavoura adjacente, a qual foi conduzida como uma lavoura comercial. O rendimento de grãos das culturas foi estimado pela colheita de amostra em uma área útil de $5,4 m^{2}$ na cultura da soja e $8,4 m^{2}$ na cultura do milho.
A precipitação pluviométrica foi determinada durante todo o período, em pluviômetro instalado a $500 \mathrm{~m}$ do experimento. Os atributos físicos do solo foram determinados em amostras coletadas com estrutura preservada, em anéis volumétricos, logo após a dessecação da pastagem, nas camadas de 0-0,05, 0,050,10, 0,10-0,15 e 0,15-0,20m de profundidade, utilizandose metodologia descrita em EMBRAPA(1997).

Os resultados foram analisados estatisticamente através da análise da variância, complementada pela aplicação de teste de comparação de médias (Tukey, $\mathrm{P}<0,05$ ), quando o teste $\mathrm{F}$ apresentou significância $\geq 95 \%$.

\section{RESULTADOS E DISCUSSÃO}

No primeiro inverno, o pastejo na área de entorno foi realizado de forma contínua por 139 dias, com lotação variando de 0,35 e 1,39UA ha-1 (Figura 1A), e, no segundo, por 76 dias, com lotação variando de 0,45 a 0,98UA ha-1 (Figura 1B), em função da entrada e saída de animais e do seu ganho de peso. Essa lotação animal determinou baixa intensidade de pastejo, o que resulta em menor deslocamento dos animais para ingerir a forragem (BAGGIO et al., 2009) e, consequentemente, menor pisoteio e risco de compactação do solo.

A precipitação pluviométrica totalizou $1.671 \mathrm{~mm}$ no primeiro e $2.345 \mathrm{~mm}$ no segundo ano agrícola, sendo relativamente bem distribuída ao longo do ano (Figuras 1A e 1B). No primeiro ano, houve deficiência hídrica a partir da floração da cultura da soja (Figura 1A), o que resultou em redução do rendimento de grãos em aproximadamente 1/3 em relação ao esperado.

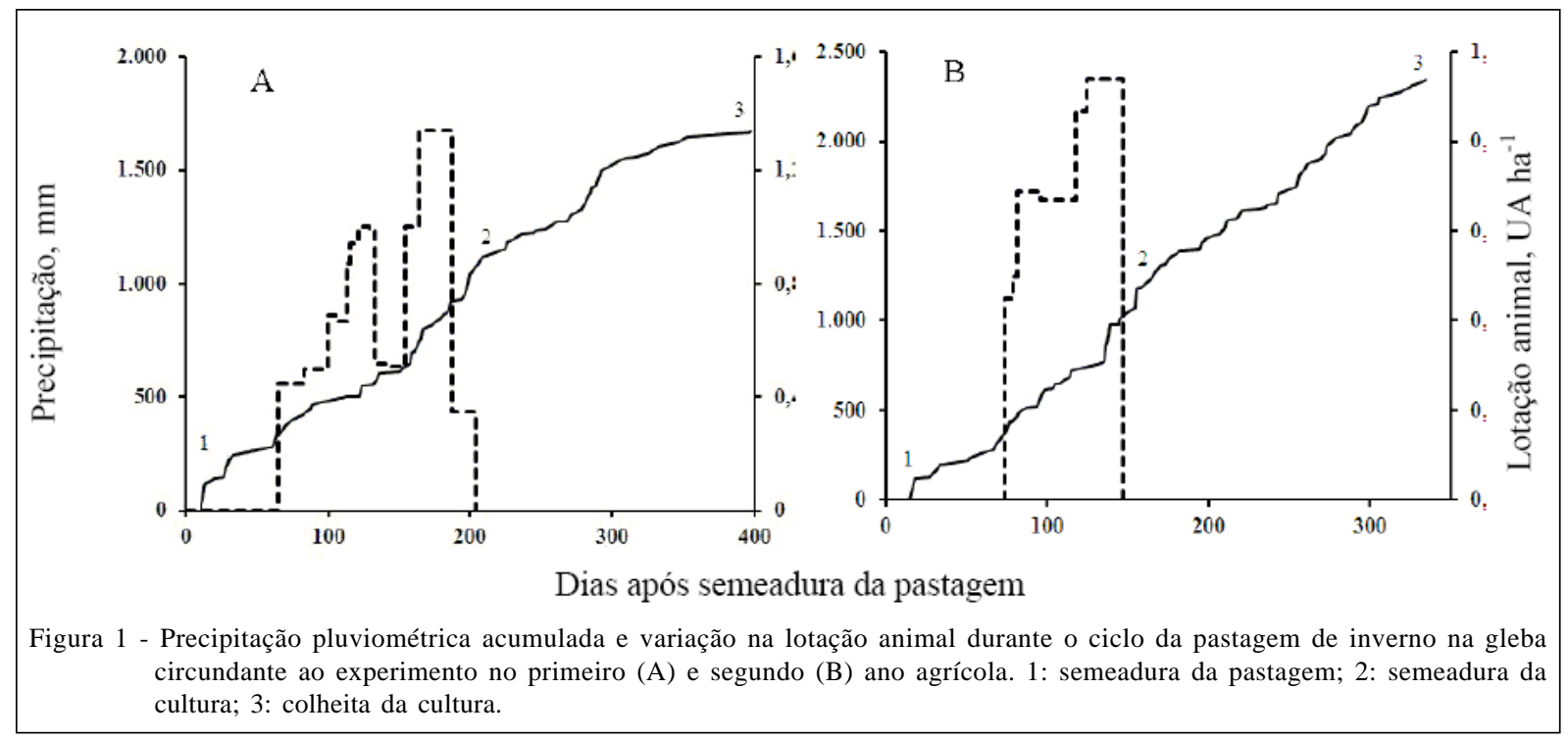

Ciência Rural, v.42, n.3, mar, 2012. 
Não foram observadas diferenças entre formas de semeadura e intervalos de diferimento da pastagem para a maioria dos atributos físicos do solo avaliados, mas foram observadas interações entre os anos agrícolas e as camadas amostradas para resistência à penetração e macro e microporosidade e entre formas de semeadura e camadas amostradas para macroporosidade (Tabela 1). Resultados semelhantes foram obtidos em outros estudos comparativos de alterações em características físicas entre os sistemas com e sem SILP(SILVA et al., 2000; SPERAet al., 2004 e 2009), entre sistemas de manejo dos animais com diferentes alturas de corte da pastagem sob pastejo (FLORES et al., 2007) e entre sistemas de uso do solo no inverno, associado ou não ao pastejo (BALBINOT JUNIOR et al., 2009b). As maiores diferenças nos atributos físicos avaliados ocorreram entre as camadas amostradas, às vezes apresentando interações dessas com os

Tabela 1 - Atributos físicos em amostras de solo coletadas em quatro camadas após a dessecação da pastagem, em dois anos de aplicação de duas formas de semeadura e quatro intervalos de diferimento da pastagem de inverno.

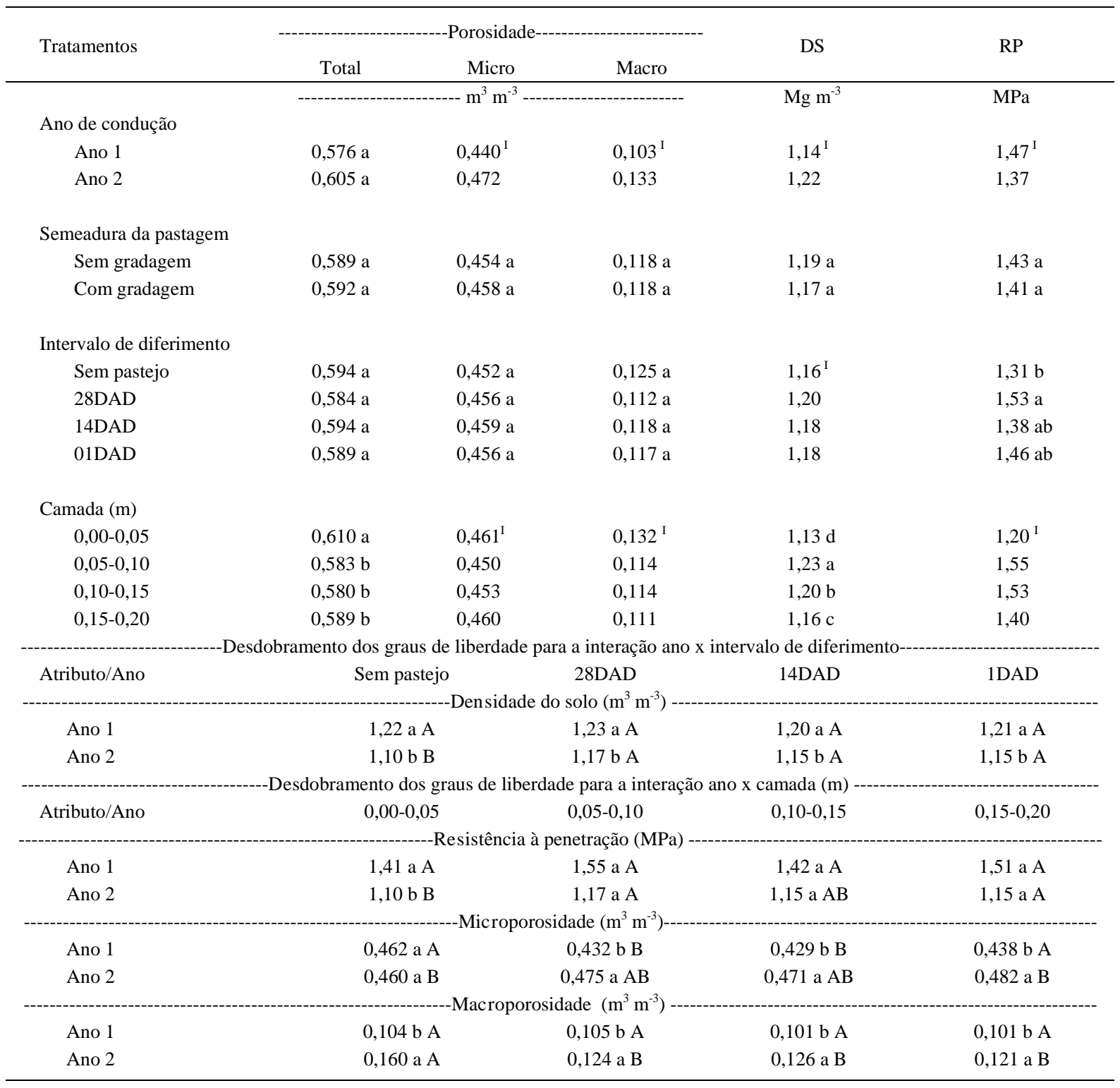

DS: densidade do solo; RP: resistência à penetração; DAD: dias antes da dessecação; I: interação entre duas fontes de variação. Médias seguidas por letras diferentes, minúsculas na coluna e maiúscula na linha, dentro de cada grupo de tratamentos, diferem estatisticamente entre si (Tukey, $\mathrm{P}<0,05$ ).

Ciência Rural, v.42, n.3, mar, 2012. 
tratamentos. Observou-se maior porosidade total e menor densidade do solo na camada de $0,00-0,05 \mathrm{~m}$, inversão desses valores na camada de $0,05-0,10 \mathrm{~m}$ e retorno paulatino aos valores encontrados na superfície com o aumento da profundidade (Tabela 1). Esses resultados diferem um pouco dos obtidos por outros autores, que encontraram maior compactação na camada superficial do solo (LANZANOVA et al., 2007), o que pode estar relacionado com a profundidade da camada amostrada, que variou entre os estudos.

A menor densidade e a maior porosidade na camada superficial, mesmo esta estando sujeita à maior influência da aplicação de pressões na superfície, podem ser explicadas tanto pela ocorrência de ciclos de umedecimento e de secagem no intervalo entre a interrupção do pisoteio e a coleta das amostras, com redução na sua densidade(HORN \& ROSTEK, 2000), como pelo maior teor de matéria orgânica nessa camada, que confere maior elasticidade ao solo (BRAIDA et al., 2008) e evita a sua deformação plástica, a qual seria irreversível em curto prazo (HORN et al., 2003). A segunda camada amostrada $(0,05-0,10 \mathrm{~cm})$, por sua vez, ainda está sujeita ao efeito da pressão aplicada pelos cascos dos animais na superfície, que resultará em deformação plástica do solo quando apresentar valor superior à sua pressão de pré-consolidação, sem reversão significativa pela elasticidade do solo e por ciclos de umedecimento e secagem nesse intervalo. A densidade do solo diminui novamente nas camadas mais profundas $(0,10-0,15$ e 0,15-0,20cm), em função da pressão aplicada na superfície ser parcialmente atenuada pelas camadas situadas acima, não atingindo, nessas camadas, valores que possam provocar compactação acentuada do solo (HORN \& ROSTEK, 2000).

No final do primeiro ciclo de pastejo, foram observados valores maiores de densidade do solo e de resistência à penetração e menores de porosidade total em relação ao final do segundo ciclo (Tabela 1), o que pode estar associado à maior lotação animal e tempo de permanência destes na lavoura, uma vez que o grau de compactação do solo é determinado tanto pela magnitude da pressão aplicada na superfície como pelo número de vezes que ela é aplicada na mesma posição (HORN et al., 2003). De forma semelhante aos resultados obtidos por SPERA et al. (2004), não foi verificado valor restritivo ao crescimento radicular nos tratamentos e camadas amostradas, tanto quando considerado o valor de densidade crítico de 1,3g cm${ }^{-3}$, estimado a partir do teor de argila desse solo (REICHERT et al., 2007), como quando considerados os valores de resistência à penetração restritivos ao crescimento radicular, que variam de 1,5 a 4,0MPa, dependendo da cultura estabelecida (OUSSIBLE et al., 1992).

O intervalo de tempo entre a retirada dos animais e a dessecação influenciou significativamente na fitomassa aérea remanescente da pastagem, com maior valor no tratamento sem pastejo (SP) e menor nos tratamentos com retirada dos animais aos 14 e um dia antes da dessecação (14DAD e 01DAD) (Tabela 2), sendo explicado pela relação entre crescimento e consumo da pastagem durante o período de permanência dos animais. A fitomassa aérea remanescente da pastagem foi maior no primeiro inverno, mesmo com maior lotação animal e intervalo de pastejo, o que pode ser explicado pela ocorrência de duas geadas severas no segundo inverno, aos 75 e 76 dias após a semeadura da pastagem, as quais prejudicaram o rebrote e até mesmo resultaram em morte de plantas.

O rendimento de grãos de soja e de milho não foi afetado pelas formas de semeadura e

Tabela 2 - Fitomassa aérea de pastagem remanescente e rendimento de grãos de soja e de milho cultivados em sucessão, em dois anos de aplicação de duas formas de semeadura e quatro intervalos de diferimento.

\begin{tabular}{|c|c|c|c|c|}
\hline \multirow[t]{2}{*}{ Tratamentos } & \multicolumn{2}{|c|}{ Fitomassa aérea da pastagem } & \multicolumn{2}{|c|}{ Rendimento de grãos } \\
\hline & Ano 1 & Ano 2 & Soja & Milho \\
\hline & ----------- & ---------- & & --------- \\
\hline \multicolumn{5}{|c|}{ Semeadura da pastagem } \\
\hline Sem gradagem & $5.765 \mathrm{a}$ & $2.113 \mathrm{a}$ & $1.994 \mathrm{a}$ & $13.054 \mathrm{a}$ \\
\hline Com gradagem & $4.604 \mathrm{a}$ & $2.094 \mathrm{a}$ & $1.949 \mathrm{a}$ & $13.238 \mathrm{a}$ \\
\hline $\mathrm{CV} \%$ & 42 & 17 & 17 & 4 \\
\hline \multicolumn{5}{|c|}{ Intervalo de diferimento } \\
\hline Sem pastejo & $7.112 \mathrm{a}$ & $3.848 \mathrm{a}$ & $1.936 \mathrm{a}$ & $13.182 \mathrm{a}$ \\
\hline $28 \mathrm{DAD}$ & $5.123 \mathrm{ab}$ & $2.048 \mathrm{~b}$ & $2.003 \mathrm{a}$ & $13.269 \mathrm{a}$ \\
\hline 14 DAD & $4.453 \mathrm{~b}$ & $1.371 \mathrm{c}$ & $1.917 \mathrm{a}$ & $13.204 \mathrm{a}$ \\
\hline 0 DAD & $4.050 \mathrm{~b}$ & $1.146 \mathrm{c}$ & 2.029 a & $12.930 \mathrm{a}$ \\
\hline $\mathrm{CV} \%$ & 42 & 26 & 13 & 5 \\
\hline
\end{tabular}

DAD: Dias antes da dessecação. Médias seguidas por letras diferentes na coluna, dentro de cada grupo de tratamentos, diferem estatisticamente entre si (Tukey, $\mathrm{P}<0,05)$. 
intervalos de diferimento da pastagem (Tabela 2), indicando que a produção da cultura cultivada em sucessão à pastagem sob pastejo direto não é afetada quando utilizada uma pressão de pastejo moderada, concordando com os resultados obtidos por SILVA et al. (2000) e LUNARDI et al. (2008). Todavia, alterações podem ocorrer no longo prazo, pois a menor produção de fitomassa aérea da pastagem de inverno, nos tratamentos com menor intervalo de diferimento, possivelmente alterarão atributos físicos e químicos do solo ao longo do tempo, principalmente no que diz respeito ao balanço do carbono orgânico (NICOLOSO et al., 2008). Tanto o baixo rendimento de grãos de soja no primeiro ano, como o alto de milho no segundo pode ser explicado pelas condições climáticas, principalmente a distribuição da precipitação pluviométrica (Figuras 1A e 1B), ocorrendo déficit hídrico no final do ciclo da soja e boa distribuição da precipitação ao longo do ciclo do milho.

\section{CONCLUSÃO}

A semeadura da pastagem anual de inverno, sem ou com revolvimento adicional do solo com grade niveladora, não altera a fitomassa aérea remanescente da pastagem e o rendimento de soja e milho cultivados em sucessão, bem como os atributos físicos do solo.

O aumento do intervalo entre a retirada dos animais e a dessecação da pastagem anual de inverno para implantação da cultura subsequente resulta em aumento na fitomassa aérea remanescente da pastagem, mas não afeta os atributos físicos do solo, exceto a resistência à penetração.

\section{AGRADECIMENTOS}

Os autores agradecem à família do Sr. José Eugênio Durigon, pela cessão da área e de insumos agrícolas para implantação do experimento, assim como pelo apoio logístico na sua condução. Trabalho executado com recursos da Fundação de Amparo à Pesquisa e Inovação do Estado de Santa Catarina (FAPESC) e do Conselho Nacional de Desenvolvimento Científico e Tecnológico (CNPq).

\section{REFERÊNCIAS}

BAGGIO, C. et al. Padrões de deslocamento e captura de forragem por novilhos em pastagem de azevém-anual e aveia-preta manejada sob diferentes alturas em sistemas de integração lavoura-pecuária. Revista Brasileira de Zootecnia, Viçosa, v.38, n.2, p.215-222, 2009. Disponível em: < http://www.scielo.br/pdf/rbz/v38n2/a01v38n2.pdf>. Acesso em: 20 mar. 2011. doi: 10.1590/S1516-35982009000200001.

BALBINOT JUNIOR, A.A. et al. Integração lavoura-pecuária: intensificação de uso de áreas agrícolas. Ciência Rural, Santa Maria, v.39, n.6, p.1925-1933, 2009a. Disponível em: <http:/ /www.scielo.br/pdf/cr/v39n6/a229cr838.pdf>. Acesso em: 20 mar. 2011. doi: 10.1590/S0103-84782009005000107.
BALBINOT JUNIOR, A.A. et al. Propriedades físicas em Cambissolo Háplico manejado sob o sistema de integração lavoura-pecuária. Revista de Ciências Agroveterinárias, Lages, v.8, n.1, p.25-34, 2009b. Disponível em: <http://rca.cav.udesc.br/ rca_2009_1/Balbinot.pdf>. Acesso em: 20 mar. 2011.

BRAIDA, J.A. et al. Resíduos vegetais na superfície e carbono orgânico do solo e suas relações com a densidade máxima obtida no ensaio proctor. Revista Brasileira de Ciência do Solo, Viçosa, v.30, n.4, p.606-614, 2006. Disponível em: <http:// www.scielo.br/pdf/rbcs/v30n4/01.pdf>. Acesso em: 20 mar. 2011. doi: 10.1590/S0100-06832006000400001.

BRAIDA, J.A. et al. Elasticidade do solo em função da umidade e do teor de carbono orgânico do solo. Revista Brasileira de Ciência do Solo, Viçosa, v.32, n.2, p.477-485, 2008. Disponível em: <http://www.scielo.br/pdf/rbcs/v32n2/02.pdf>. Acesso em: 10 mar. 2011. doi: 10.1590/S0100-06832008000200002.

EMPRESA BRASILEIRA DE PESQUISA AGROPECUÁRIA. Centro Nacional de Pesquisa em Solos. Manual de métodos de análise do solo. Rio de Janeiro: Embrapa, 1997. 212p.

EMPRESA BRASILEIRA DE PESQUISA AGROPECUÁRIA. Centro Nacional de Pesquisa em Solos. Solos do Estado de Santa Catarina. Rio de Janeiro: EMBRAPA/CNPS, 2004. CD-ROM.; mapa color. (Embrapa Solos. Boletim de Pesquisa e Desenvolvimento; n. 46).

FLORES, J.P.C. et al. Atributos físicos do solo e rendimento de soja em sistema plantio direto em integração lavoura pecuária com diferentes pressões de pastejo. Revista Brasileira de Ciência do Solo, Viçosa, v.31, n.4, p.771-780, 2007.

FONTANELI, R.S. et al. Lucratividade e risco de sistemas de produção de grãos com pastagens, sob sistema plantio direto. Ciência Rural, Santa Maria, v.36, n.1, p.51-57, 2006. Disponível em: <http://www.scielo.br/pdf/cr/v36n1/a08v36n1.pdf>. Acesso em: 10 mar. 2011. doi: 10.1590/S0103-84782006000100008.

HORN, R.; ROSTEK, J. Subsoil compaction processes - satate of knowledge. In: HORN, R. et al. Subsoil compaction: distribution, processes and consequences. Reiskirchen: Catena Verlag, 2000. p.44-54. (Advances in geoecology, 32).

HORN, R. et al. Effect of repeated tractor wheeling on stress/ strain properties and consequences on physical properties in structured arable soils. Soil \& Tillage Research, Amsterdam, v.73, p.101-106, 2003.

LANZANOVA, M.E. et al. Atributos físicos do solo em sistema de integração lavoura-pecuária sob plantio direto. Revista Brasileira de Ciência do Solo, Viçosa, v.31, n.5, p.11311140, 2007. Disponível em: <http://www.scielo.br/pdf/rbcs/ v31n5/a28v31n5.pdf>. Acesso em: 20 mar. 2011. doi: 10.1590/ S0100-06832007000500028.

LUNARDI, R. et al. Rendimento de soja em sistema de integração lavoura pecuária: efeitos de métodos e intensidades de pastejo. Ciência Rural, Santa Maria, v.38, n.3, p.795801, 2008. Disponível em: <http://www.scielo.br/pdf/cr/v38n3/ a32v38n3.pdf $>$. Acesso em: 20 mar. 2011. doi: 10.1590/ S0103-84782008000300032.

NICOLOSO, R.S. et al. Balanço de carbono orgânico no solo sob integração lavoura-pecuária no sul do Brasil. Revista Brasileira de Ciência do Solo, v.32, p.2425-2433, 2008. Disponível em: <http://www.scielo.br/pdf/rbcs/v32n6/v32n6a20.pdf>. Acesso em: 20 mar. 2011. doi: 10.1590/S0100-06832008000600020. 
OUSSIBLE, M. et al. Subsurface compaction reduces the root and shoot growth and grain yield of wheat. Agronomy Journal, Madison, v.84, n.1, p.34-38, 1992.

PANDOLFO, C. et al. Atlas climatológico digital do Estado de Santa Catarina. Florianópolis: Epagri, 2002.

REICHERT, J.M. et al. Compactação do solo em sistemas agropecuários e florestais: identificação, efeitos, limites críticos e mitigação. In: CERETTA, C.A. et al. Tópicos em Ciência do Solo. Viçosa: Sociedade Brasileira de Ciência do Solo, 2007. V.5, p.49-134.

SILVA, V.R. et al. Densidade do solo, atributos químicos e sistema radicular do milho afetados pelo pastejo e manejo do solo. Revista Brasileira de Ciência do Solo, Viçosa, v.24, n.2, p.191-199, 2000.
SPERA, S.T. et al. Efeitos de sistemas de produção de grãos envolvendo pastagens sob plantio direto nos atributos físicos de solo e na produtividade. Revista Brasileira de Ciência do Solo, Viçosa, v.28, n.3, p.533-542, 2004. Disponível em: <http://www.scielo.br/pdf/rbcs/v28n3/a14v28n3.pdf>. Acesso em: 20 mar. 2011. doi: 10.1590/S0100-06832004000300014.

SPERA, S.T. et al. Integração lavoura-pecuária e os atributos físicos do solo manejado sob sistema plantio direto. Revista Brasileira de Ciência do Solo, Viçosa, v.33, n.1, p.129136, 2009. Disponível em: <http://www.scielo.br/pdf/rbcs/ v33n1/14.pdf>. Acesso em: 20 nov. 2011. doi: 10.1590/S010006832009000100014 .

VEIGA, M. et al. Soil compressibility and penetrability of an Oxisol from southern Brazil, as affected by long-term tillage systems. Soil \& Tillage Research, Amsterdam, v.92, p.104113, 2007. 